\title{
Effects of a liquid high-fat meal on postprandial lipid metabolism in type 2 diabetic patients with abdominal obesity
}

Feng Wang ${ }^{1}$, Huixia Lu ${ }^{2}$, Fukang Liu' ${ }^{1}$, Huizhen Cai ${ }^{1,3}$, Zhixiu Song ${ }^{1,4}$, Fei Guo ${ }^{2}$, Yulan Xie ${ }^{2}$, Guofang Shu ${ }^{2}$ and Guiju Sun ${ }^{1 *}$

\begin{abstract}
Background: Postprandial lipemia and lipoprotein lipase (LPL) activity play crucial roles in the pathogenesis of accelerated atherosclerosis. This study aimed to evaluate the postprandial lipid metabolism after the ingestion of a liquid high-fat meal in type 2 diabetic patients with abdominal obesity, and determine if the Pvull polymorphisms of LPL influence their postprandial lipid responses.

Methods: Serum glucose, insulin, triglycerides (TG), total cholesterol (TC) and high density lipoprotein cholesterol ( $\mathrm{HDL}-\mathrm{C})$ were measured in fasting and postprandial state at 0.5, 1, 2, 4, 6 and $8 \mathrm{~h}$ after a liquid high-fat meal in 51 type 2 diabetic patients with abdominal obesity, 31 type 2 diabetic patients without abdominal obesity and 39 controls. Their Pvull polymorphisms of LPL were tested in fasting.

Results: Type 2 diabetic patients with abdominal obesity had significantly higher postprandial areas under the curve (AUC) of glucose [least square mean difference $(\mathrm{LSMD})=30.763,95 \%$ confidence interval $(C \mathrm{Cl})=23.071-38.455, F=37.346$, $P<0.05]$ and $T C(L S M D=3.995,95 \% C l=1.043-6.947, F=3.681, P<0.05)$ than controls. Postprandial AUCs for insulin, homeostasis model assessment-insulin resistance (HOMA-IR) and TG were higher (LSMD $=86.987,95 \% \mathrm{Cl}=37.421-136$. $553, F=16.739, P<0.05 ; \mathrm{LSMD}=37.456,95 \% \mathrm{Cl}=16.312-58.600, F=27.012, P<0.05 ; \mathrm{LSMD}=4.684,95 \% \mathrm{Cl}=2.662-6$. $705, F=26.158, P<0.05)$, whereas HDL-C AUC was lower $(\mathrm{LSMD}=-1.652,95 \% \mathrm{Cl}=-2.685--0.620, F=8.190, P<0.05)$ in type 2 diabetic subjects with abdominal obesity than those without abdominal obesity. In type 2 diabetic patients with abdominal obesity, postprandial TG AUC was lower in $\mathrm{P}-/-$ than in $\mathrm{P}+/-(\mathrm{LSMD}=-4.393,95 \% \mathrm{Cl}=-9.278--0.491$, $F=4.476, P<0.05)$ and $P+/+(L S M D=-7.180,95 \% C l=-12.319--2.014, F=4.476, P<0.05)$ phenotypes. Postprandial AUCs for glucose, insulin, HOMA-IR, TC and HDL-C were not different according to Pvull phenotypes.

Conclusions: Abdominal obesity exacerbates the postprandial lipid responses in type 2 diabetic patients, which partly explains the excess atherogenic risk in these patients. In addition, the presence of $\mathrm{P}+$ allele could contribute to a greater postprandial TG increase in type 2 diabetic patients with abdominal obesity.
\end{abstract}

Trial registration: ChiCTR-IOR-16008435. Registered 8 May 2016.

Keywords: Type 2 diabetes, Abdominal obesity, Liquid high-fat meal, Lipid metabolism, Pvull polymorphisms

\footnotetext{
* Correspondence: gjsun@seu.edu.cn

${ }^{1}$ Key Laboratory of Environmental Medicine and Engineering of Ministry of Education, and Department of Nutrition and Food Hygiene, School of Public Health, Southeast University, Nanjing, China

Full list of author information is available at the end of the article
} 


\section{Background}

It is generally known that individuals were in the state of not fasting during most of the time. Determination of blood lipids, however, is mostly based on the fasting condition. This mode of detection does not accurately reflect the level of lipids. In 1979, Zilversmit first proposed that postprandial lipemia was associated with an increased risk of atherosclerosis [1].This finding attracted growing attention in postprandial lipid metabolism and confirmed by others [2, 3]. At present, postprandial lipid disturbance have been seen in persons with obesity [4-6], impaired glucose tolerance [7], first degree relatives of type 2 diabetes families [8], and type 2 diabetes [9-13].

Type 2 diabetes is a global epidemic that poses an immense medical challenge to health-care systems. Abdominal obesity that accompanies type 2 diabetes is frequently associated with atherogenic dyslipidemia [14]. In addition, lipoprotein lipase (LPL) also plays a pivotal role in lipid homeostasis [15]. The Pvull polymorphisms are found in intron 6 of the LPL gene. This genetic polymorphisms might influence the risk of the appearance of coronary arterial disease [16]. However, the effects of PvuII polymorphisms of LPL on postprandial lipid profiles in response to a liquid high-fat meal have not been reported so far in type 2 diabetic patients with abdominal obesity.

Therefore, the aims of this study were to evaluate the postprandial lipid responses after the ingestion of a liquid high-fat meal in type 2 diabetic patients with abdominal obesity, and determine if the PvuII polymorphisms of LPL influence their postprandial lipid metabolism.

\section{Methods}

\section{Subjects}

The study was conducted in 51 type 2 diabetic patients with abdominal obesity and 31 type 2 diabetic patients without abdominal obesity, recruited from the Nanjing Jiangpu People Hospital. A group of 39 non-diabetic, non-abdominal obesity controls of similar age was also included (Fig. 1). The sample size was estimated after fixing $\alpha$ value at 0.05 and margin of error at $0.5(\mathrm{SD}=1.3)$ for triglyceride (TG) by PASS 11. Diagnosis of type 2 diabetes was based on World Health Organization criteria [17]. Abdominal obesity was defined by Working Group on Obesity of China criteria (waistline $\geq 85 \mathrm{~cm}$ for male and $\geq 80 \mathrm{~cm}$ for female) [18]. All subjects had normal fasting TG level $(<1.7 \mathrm{mmol} / \mathrm{L})$, normal thyroid, hepatic and renal functions. They were not taking any drug known to influence lipid metabolism. The study protocol was approved by the ethic committee of Zhongda hospital affiliated to Southeast University, and written informed consent was obtained from each participant before being tested.

\section{Study protocol}

After a 10-12 h overnight fast, fasting venous blood samples were gathered by an indwelling needle fitted in the subjects' cubital veins. Following this, a liquid highfat meal was given to be ingested in $5 \mathrm{~min}$. The $1000 \mathrm{ml}$ test drink was formulated by adding casein $72 \mathrm{~g}$, sucrose $156 \mathrm{~g}$, lactose $12 \mathrm{~g}$, butter $132 \mathrm{~g}$, cholesterol $1.32 \mathrm{~g}$ and $7 \mathrm{~g}$ monostearin. Its manufacturing process involves heating, mixing, shearing, homogenizing, packaging and autoclaving. The corresponding caloric intake was $20 \mathrm{kcal} / \mathrm{kg}$ body weight, $56.9 \%$ derived from fat $(31.9 \%$ saturated fatty acids, $22.0 \%$ monounsaturated fatty acids, and $3.0 \%$ polyunsaturated fatty acids), 30.5\% from carbohydrate, and $12.6 \%$ from protein. Preparation of the liquid high-fat meal took place in Taizhou Weigang dairy food corporation under the supervision of Nanjing $\mathrm{Mu}$ nicipal Center for Disease Control and Prevention. Subjects were prohibited from strenuous exercise and

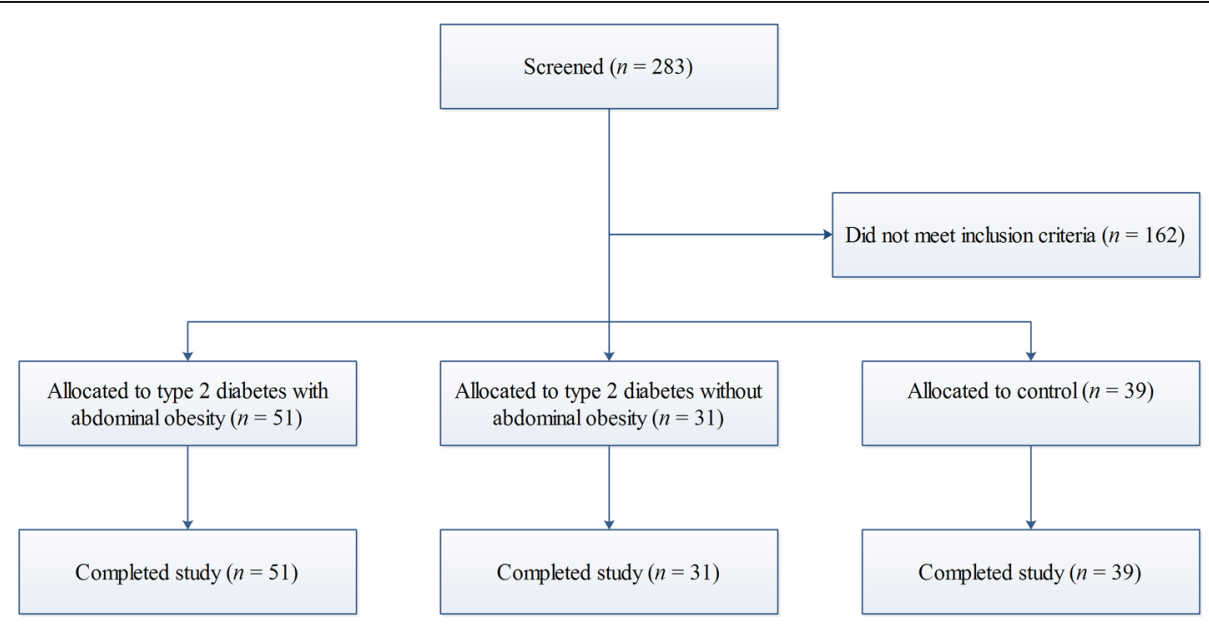

Fig. 1 Study flow chart of participant selection 
permitted to consume only water throughout the postprandial period. All subjects were able to eat the entire test meal. At baseline and 0.5, 1, 2, 4, 6 and $8 \mathrm{~h}$ after the meal, serum glucose, insulin, TG, total cholesterol (TC) and high density lipoprotein cholesterol (HDL-C) were determined. The PvuII polymorphisms of LPL were tested only in fasting.

\section{Measurements}

Waistline, weight and height were measured according to standardized protocols. Serum glucose, TG, TC and HDL-C were performed by automatic biochemical analyzer (Beckman, DxC800, USA). Serum insulin was determined by chemiluminescence (Roche, FG_cobase 8000, Switzerland). The insulin resistance was estimated using homeostasis model assessment-insulin resistance (HOMA-IR) formula [19]. The postprandial areas under the curve (AUC) was calculated using GraphPad Prism 5. The PvuII polymorphisms of LPL were performed by DNA extraction, polymerase chain reaction, and PvuII restriction enzyme digestion of the amplified products.

\section{Statistical analysis}

Data are expressed as means $\pm \mathrm{SD}$, unless otherwise stated. For comparison among groups, analysis of variance (ANOVA) with post hoc test were used. For comparison overtime, repeated measures ANOVA were used. Variables not normally distributed were analyzed after logarithmic transformation or by nonparametric tests. Chisquare test was used for categorical variables. Statistical analysis were performed in PASW statistics 18.0. A value of $P<0.05$ was considered as statistically significant.

\section{Results}

Baseline characteristics

The baseline characteristics of all participants are summarized in Table 1. The three groups did not differ by age, sex ratio and PvuII phenotypes. Duration of diabetes, diabetes treatment, glucose, TG, TC and HDL-C were similar in type 2 diabetic patients with and without abdominal obesity. Waistline, body mass index, insulin and HOMA-IR were significantly higher (all $P<0.05$ ) in type 2 diabetic subjects with abdominal obesity than those without abdominal obesity and controls.

Table 1 Baseline characteristics of all participants

\begin{tabular}{|c|c|c|c|}
\hline Variables & $\begin{array}{l}\mathrm{T} 2 \mathrm{D}+\mathrm{AO} \\
(n=51)\end{array}$ & $\begin{array}{l}\text { T2D-AO } \\
(n=31)\end{array}$ & $\begin{array}{l}\text { Control } \\
(n=39)\end{array}$ \\
\hline Age, years & $56.6 \pm 7.5$ & $53.4 \pm 9.2$ & $52.8 \pm 9.3$ \\
\hline Male / female, $\mathrm{n}$ & $29 / 22$ & $16 / 15$ & $21 / 18$ \\
\hline Duration of diabetes, years (median, IQR) & $4.0(2.0-8.0)$ & $3.0(2.0-5.5)$ & - \\
\hline \multicolumn{4}{|l|}{ Diabetes treatment, $\mathrm{n}$} \\
\hline Diet only & 3 & 2 & - \\
\hline Oral agents & 38 & 24 & - \\
\hline Insulin & 4 & 2 & - \\
\hline Insulin + oral agents & 6 & 3 & - \\
\hline Waistline, cm & $91.7 \pm 5.9^{a, b}$ & $76.6 \pm 4.8$ & $76.6 \pm 4.9$ \\
\hline $\mathrm{BMl}, \mathrm{kg} / \mathrm{m}^{2}$ & $25.2 \pm 2.7^{\mathrm{a}, \mathrm{b}}$ & $21.1 \pm 2.0$ & $21.7 \pm 2.1$ \\
\hline Glucose, mmol/L & $7.89 \pm 2.06^{\mathrm{a}}$ & $7.74 \pm 2.71^{c}$ & $5.07 \pm 0.41$ \\
\hline Insulin, ulU/mL (median, IQR) & $11.35(9.42-16.07)^{a, b}$ & $8.57(6.59-11.77)^{c}$ & $6.93(5.06-9.24)$ \\
\hline HOMA-IR (median, IQR) & $4.27(3.06-5.97)^{a, b}$ & $2.80(1.93-4.09)^{c}$ & $1.51(1.15-2.08)$ \\
\hline $\mathrm{TG}, \mathrm{mmol} / \mathrm{L}$ & $1.11 \pm 0.34^{a}$ & $0.79 \pm 0.35$ & $0.77 \pm 0.31$ \\
\hline $\mathrm{TC}, \mathrm{mmol} / \mathrm{L}$ & $4.80 \pm 0.90^{a}$ & $4.66 \pm 0.81$ & $4.32 \pm 0.85$ \\
\hline $\mathrm{HDL}-\mathrm{C}, \mathrm{mmol} / \mathrm{L}$ & $1.24 \pm 0.28^{a}$ & $1.45 \pm 0.30$ & $1.49 \pm 0.36$ \\
\hline \multicolumn{4}{|l|}{ Pvull phenotypes, n } \\
\hline $\mathrm{P}+/+$ & 31 & 16 & 14 \\
\hline $\mathrm{P}+/-$ & 16 & 11 & 19 \\
\hline $\mathrm{P}-/-$ & 4 & 4 & 6 \\
\hline
\end{tabular}

All data are means \pm SD unless otherwise stated. T2D + AO, type 2 diabetes with abdominal obesity; T2D-AO, type 2 diabetes without abdominal obesity; IQR, interquartile range; $\mathrm{BMI}$, body mass index; HOMA-IR, homeostasis model assessment-insulin resistance; TG, triglyceride; TC, total cholesterol; $\mathrm{HDL}-\mathrm{C}$, high density lipoprotein cholesterol. a $P<0.05, \mathrm{~T} 2 \mathrm{D}+\mathrm{AO}$ vs control, ${ }^{\mathrm{b}} \mathrm{P}<0.05, \mathrm{~T} 2 \mathrm{D}+\mathrm{AO}$ vs T2D-AO, ${ }^{\mathrm{c}} P<0.05, \mathrm{~T} 2 \mathrm{D}-\mathrm{AO}$ vs control 


\section{Postprandial glycemic status}

For the serum glucose, insulin and HOMA-IR responses, there was a significant time effect $(P<0.05)$, group effect $(P<0.05)$ and group $\times$ time interaction $(P<0.05)$. In type 2 diabetic patients with abdominal obesity, glucose levels increased between 0.5 and $2 \mathrm{~h}$, in concomitance with the increase in insulin and HOMA-IR (Fig. 2a-c). Glucose levels showed a peak at $0.5 \mathrm{~h}$ in controls and at $1 \mathrm{~h}$ in type 2 diabetic patients without abdominal obesity (Fig. 2a), insulin and HOMA-IR levels rose significantly in both groups with peak at $1 \mathrm{~h}$ (Fig. $2 \mathrm{~b}-\mathrm{c}$ ).

Type 2 diabetic patients with abdominal obesity had significantly higher postprandial glucose AUC $(\mathrm{LSMD}=30.763,95 \% \mathrm{CI}=23.071-38.455, F=37.346$, $P<0.05$ ) than controls (Fig. 2d). Type 2 diabetic patients with abdominal obesity had higher postprandial AUCs for insulin $(\mathrm{LSMD}=86.987,95 \% \mathrm{CI}=37.421-136.553$, $F=16.739, P<0.05)$ and HOMA-IR $($ LSMD $=37.456$,
95\% CI $=16.312-58.600, F=27.012, P<0.05)$ than those without abdominal obesity (Fig. 2e-f).

\section{Postprandial lipid status}

For the serum TG and TC responses, there was a significant time effect $(P<0.05)$, group effect $(P<0.05)$ and group $\times$ time interaction $(P<0.05)$. For the serum HDL-C responses, there was a significant time effect $(P<0.05)$ and group effect $(P<0.05)$. In type 2 diabetic patients with abdominal obesity, TG levels reached peak concentration at $4 \mathrm{~h}$, and had not returned to fasting concentration at $8 \mathrm{~h}$ (Fig. 3a). A significant reduction was observed in TC and HDL-C levels when compared with their fasting concentration (Fig. 3b-c). In both controls and type 2 diabetic patients without abdominal obesity, TG levels peaked at $4 \mathrm{~h}$ and had returned to fasting concentration at $8 \mathrm{~h}$ (Fig. 3a), TC and HDL-C levels followed a decreasing trend over time (Fig. $3 \mathrm{~b}-\mathrm{c}$ ).
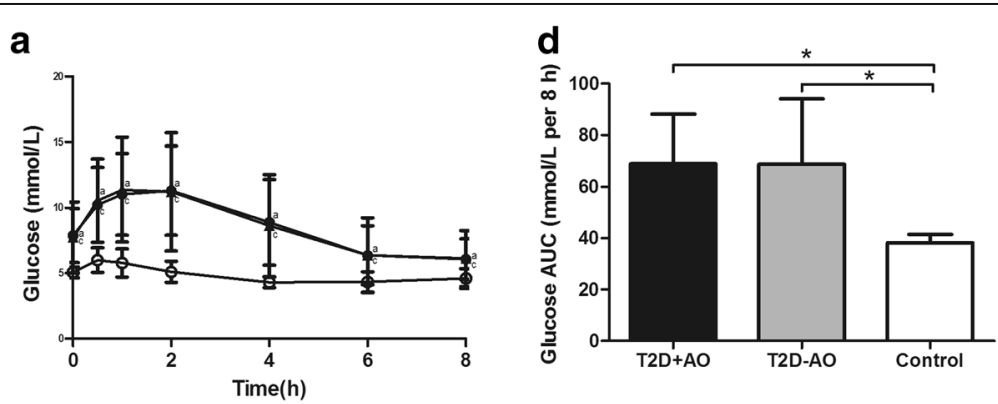

b
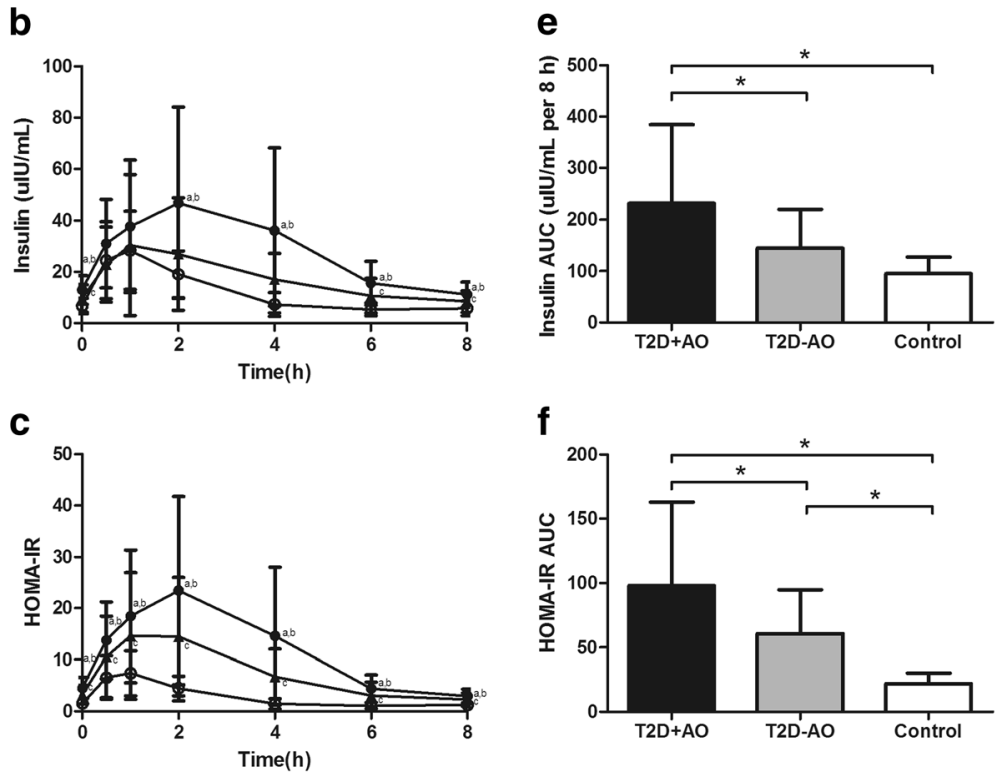

Fig. 2 Postprandial glycemic status in different study groups. Left panel: Serum (a) glucose, (b) insulin and (c) HOMA-IR levels over the postprandial period in different study groups. Plotted values are means \pm SD. $\bullet, T 2 D+A O(n=51) ; \boldsymbol{\Lambda}$, T2D-AO $(n=31) ; 0$, Control $(n=39)$. ${ }^{a}$ $P<0.05, \mathrm{~T} 2 \mathrm{D}+\mathrm{AO}$ vs control, ${ }^{\mathrm{b}} P<0.05, \mathrm{~T} 2 \mathrm{D}+\mathrm{AO}$ vs T2D-AO, ${ }^{\mathrm{c}} P<0.05, \mathrm{~T} 2 \mathrm{D}-\mathrm{AO}$ vs control. For the serum glucose, insulin and HOMA-IR responses, there was a significant time effect $(P<0.05)$, group effect $(P<0.05)$ and group $\times$ time interaction $(P<0.05)$ by repeated-measures ANOVA. Right panel: Postprandial (d) glucose, (e) insulin and (f) HOMA-IR AUCs in different study groups. Bars represent means \pm SD. ${ }^{*} P<0.05$. $\mathrm{T} 2 \mathrm{D}+\mathrm{AO}$, type 2 diabetes with abdominal obesity; T2D-AO, type 2 diabetes without abdominal obesity; HOMA-IR, homeostasis model assessment-insulin resistance; AUC, areas under the curve 

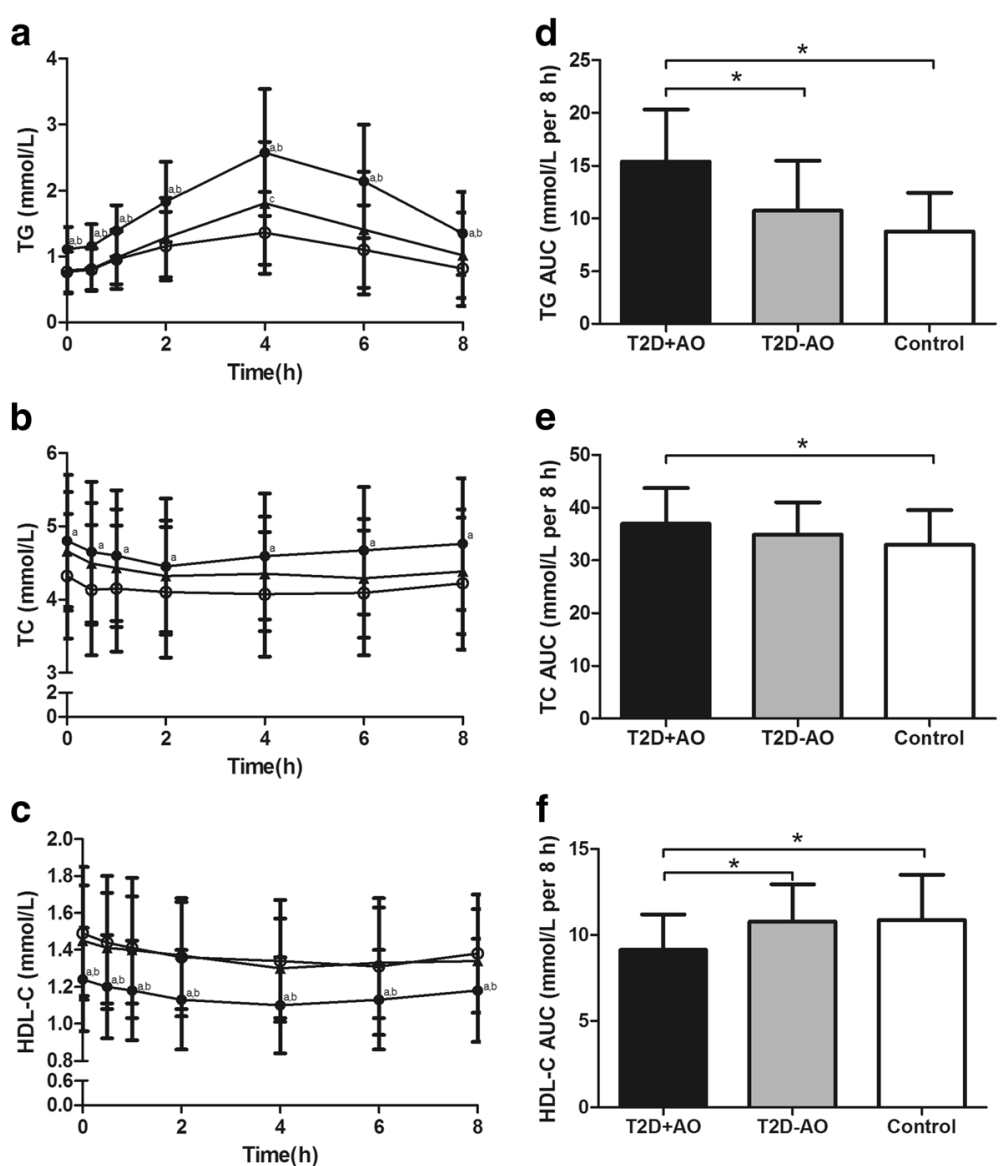

Fig. 3 Postprandial lipid status in different study groups. Left panel: Serum (a) TG, (b) TC and (c) HDL-C levels over the postprandial period in different study groups. Plotted values are means $\pm \mathrm{SD}$. $\bullet$, T2D + AO $(n=51) ; \boldsymbol{\Delta}$, T2D-AO $(n=31) ; 0$, Control $(n=39)$. ${ }^{a} P<0.05, T 2 D+\mathrm{AO}$ vs control, ${ }^{\mathrm{b}} P<0.05, \mathrm{~T} 2 \mathrm{D}+\mathrm{AO}$ vs T2D-AO, ${ }^{\mathrm{C}} P<0.05, \mathrm{~T} 2 \mathrm{D}-\mathrm{AO}$ vs control. For the serum TG and TC responses, there was a significant time effect $(P<0.05)$, group effect $(P<0.05)$ and group $\times$ time interaction $(P<0.05)$ by repeated-measures ANOVA. For the serum HDL-C responses, there was a significant time effect $(P<0.05)$ and group effect $(P<0.05)$ by repeated-measures ANOVA. Right panel: Postprandial (d) TG, (e) TC and $(\mathbf{f})$ HDL-C AUCs in different study groups. Bars represent means \pm SD. ${ }^{*} P<0.05$. T2D + AO, type 2 diabetes with abdominal obesity; T2D-AO, type 2 diabetes without abdominal obesity; TG, triglyceride; TC, total cholesterol; HDL-C, high density lipoprotein cholesterol; AUC, areas under the curve

Postprandial TG AUC (Fig. 3d) was higher $(\mathrm{LSMD}=4.684,95 \% \mathrm{CI}=2.662-6.705, F=26.158$, $P<0.05$ ), whereas HDL-C AUC (Fig. 3f) was lower $(\mathrm{LSMD}=-1.652,95 \% \mathrm{CI}=-2.685--0.620, F=8.190$, $P<0.05)$ in type 2 diabetic patients with abdominal obesity than those without abdominal obesity. Type 2 diabetic patients with abdominal obesity had significantly higher postprandial TC AUC (LSMD $=3.995,95 \% \mathrm{CI}=1.043-$ 6.947, $F=3.681, P<0.05$ ) than controls (Fig. 3e).

The influence of Pvull polymorphisms on postprandial glycemic and lipid status

We compared glycemic and lipid responses in type 2 diabetic subjects with abdominal obesity according to PvuII phenotypes. The three phenotypic groups did not differ in demographic characteristics, fasting glycemic and lipid parameters (Table 2).
After the liquid high-fat meal, glucose, insulin and HOMA-IR levels were not different according to PvuII phenotypes (Fig. $4 \mathrm{a}-\mathrm{C}$ ). TG levels were lower in $\mathrm{P}-/-$ than in $\mathrm{P}$ $-/+$ and $\mathrm{P}+/+$ patients, with the difference reaching significance at $4 \mathrm{~h}$ (Fig. 5a). TC and HDL-C levels were lower in $\mathrm{P}$ $-/-$ than in $\mathrm{P}-/+$ and $\mathrm{P}+/+$ patients, but this difference did not reach significance (Fig. $5 \mathrm{~b}-\mathrm{c}$ ). The postprandial TG AUC was lower in $\mathrm{P}-/-$ than in $\mathrm{P}+/-(\mathrm{LSMD}=-4.393,95 \%$ $\mathrm{CI}=-9.278-0.491, F=4.476, P<0.05)$ and $\mathrm{P}+/+$ $(\mathrm{LSMD}=-7.180,95 \% \mathrm{CI}=-12.319--2.014, F=4.476$, $P<0.05$ ) patients (Fig. $5 \mathrm{~d}$ ), whereas postprandial AUCs for glucose, insulin, HOMA-IR (Fig. 4d-f), TC and HDL-C (Fig. $5 e-f)$ were not different in the three phenotypic groups.

\section{Discussion}

In this study, we assess the postprandial lipid responses after a high-fat challenge in type 2 diabetic patients with abdominal obesity, and determine whether the PvuII 
Table 2 Baseline characteristics of type 2 diabetic patients with abdominal obesity according to Pvull phenotype

\begin{tabular}{|c|c|c|c|}
\hline Variables & $\begin{array}{l}\mathrm{P}+/+ \\
(n=31)\end{array}$ & $\begin{array}{l}P+/- \\
(n=16)\end{array}$ & $\begin{array}{l}\mathrm{P}-/- \\
(n=4)\end{array}$ \\
\hline Age, years & $56.2 \pm 7.8$ & $57.1 \pm 7.5$ & $56.3 \pm 7.6$ \\
\hline Male / female, $\mathrm{n}$ & $18 / 13$ & $9 / 7$ & $2 / 2$ \\
\hline Duration of diabetes, years (median, IQR) & $5.0(2.0-9.0)$ & $4.0(1.0-4.5)$ & $3.5(2.5-4.5)$ \\
\hline \multicolumn{4}{|l|}{ Diabetes treatment, $\mathrm{n}$} \\
\hline Diet only & 2 & 1 & 0 \\
\hline Oral agents & 22 & 12 & 4 \\
\hline Insulin & 3 & 1 & 0 \\
\hline Insulin + oral agents & 4 & 2 & 0 \\
\hline Waistline, cm & $90.9 \pm 5.6$ & $92.8 \pm 6.8$ & $90.3 \pm 3.8$ \\
\hline $\mathrm{BMI}, \mathrm{kg} / \mathrm{m}^{2}$ & $25.3 \pm 2.7$ & $25.4 \pm 2.5$ & $25.5 \pm 4.6$ \\
\hline Glucose, $\mathrm{mmol} / \mathrm{L}$ & $7.98 \pm 1.89$ & $7.52 \pm 2.39$ & $8.17 \pm 2.30$ \\
\hline Insulin, ulU/mL (median, IQR) & $11.35(9.59-15.56)$ & $11.95(9.45-18.10)$ & $10.58(8.05-11.55)$ \\
\hline HOMA-IR (median, IQR) & $4.31(3.19-5.68)$ & $4.21(2.85-6.16)$ & $3.61(2.56-4.68)$ \\
\hline $\mathrm{TG}, \mathrm{mmol} / \mathrm{L}$ & $1.22 \pm 0.35$ & $1.16 \pm 0.29$ & $0.78 \pm 0.35$ \\
\hline $\mathrm{TC}, \mathrm{mmol} / \mathrm{L}$ & $4.83 \pm 0.98$ & $4.76 \pm 0.82$ & $4.47 \pm 0.80$ \\
\hline $\mathrm{HDL}-\mathrm{C}, \mathrm{mmol} / \mathrm{L}$ & $1.22 \pm 0.29$ & $1.27 \pm 0.28$ & $1.11 \pm 0.13$ \\
\hline
\end{tabular}

All data are means \pm SD unless otherwise stated. IQR interquartile range, BMI body mass index, HOMA-IR homeostasis model assessment-insulin resistance, TG triglyceride, TC, total cholesterol, HDL-C high density lipoprotein cholesterol

polymorphisms of LPL influence their postprandial lipid metabolism. As expected, type 2 diabetic patients with abdominal obesity had higher postprandial AUCs for insulin and HOMA-IR than those without abdominal obesity and controls, suggesting greater degree of insulin resistance. Type 2 diabetic patients with abdominal obesity, even with fasting normotriglyceridaemia, showed higher postprandial TG AUC and lower postprandial HDL-C AUC than those without abdominal obesity and controls. Moreover, in type 2 diabetic patients with abdominal obesity, the patients with at least one P+ allele had a greater TG AUC than P-/- patients.

After the high-fat load, we observed a significant TG increase at $4 \mathrm{~h}$ in both type 2 diabetic patients and controls. This finding concurs with most previous studies $[5,7,9$, $11,20,21]$. However, only type 2 diabetic patients with abdominal obesity showed greater TG level after $8 \mathrm{~h}$, thus indicating a decreased TG-clearing capacity. In addition, postprandial TG AUC was not different from controls in type 2 diabetic patients without abdominal obesity. Similar results have been previously observed in non-obese type 2 diabetic patients $[22,23]$. The postprandial TG increase in all groups was mirrored by a concomitant decrease in HDL-C. Previous studies conducted in normolipemic [24] and hypercholesterolemic [25] postmenopausal women also found a significant decrease in HDL-C after ingestion of an oral fat load. Interestingly, although postprandial TC AUC was higher in type 2 diabetic subjects with abdominal obesity than controls, a decreased TC levels have also been observed in all groups when compared with their fasting concentration. Reasons for this phenomenon may be that high level of dietary cholesterol suppress the production of cholesterol in erythrocytes [26]. This finding confirms previous studies carried out in diabetic obese [20] and normotriglyceridemic subjects [6]. An important thing to note is that postprandial AUCs for TG, TC and HDL-C were not statistically significant between type 2 diabetic patients without abdominal obesity and controls. Thus, type 2 diabetes by itself does not seem to be sufficient to cause deterioration of postprandial lipid profiles.

LPL is a key enzyme of lipid metabolism, its primary function is to provide free fatty acids and glycerol for energy utilization and storage [27]. Several mutations in the LPL gene will have influence on catabolism of lipoproteins. Recent data suggest that the PvuII polymorphisms of LPL play critical roles in the development of metabolic and cardiovascular disease $[28,29]$. However, the influences of PvulI polymorphisms on postprandial lipemia in type 2 diabetic patients with abdominal obesity have not been reported to date. There are, to our knowledge, only 1 previous study assessed association of PvuII polymorphisms of LPL with lipid metabolism in type 2 diabetic patients [30]. This study displayed a higher TG level in $\mathrm{P}+/+$ subjects, indicating a modulating role of $\mathrm{P}$ allele on lipid profile. It is likely that the difference would have been more evident after a high-fat meal. The HindIII variant is another characterized polymorphisms of LPL. Pirro et al. [24] assessed the role of HindIII polymorphisms of LPL in hyperlipemic postmenopausal women and found that TG AUC was significantly higher in $\mathrm{H}+$ allele carriers than in subjects with $\mathrm{H}-/$ - genotype. 
a

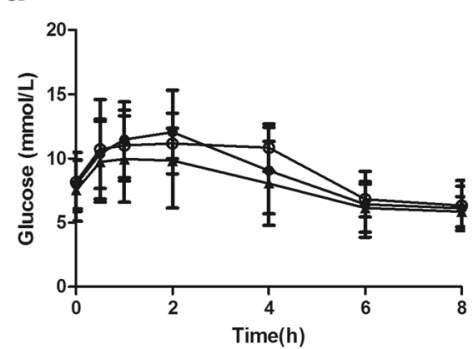

b

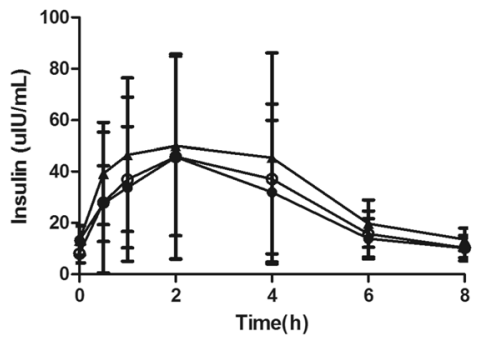

C

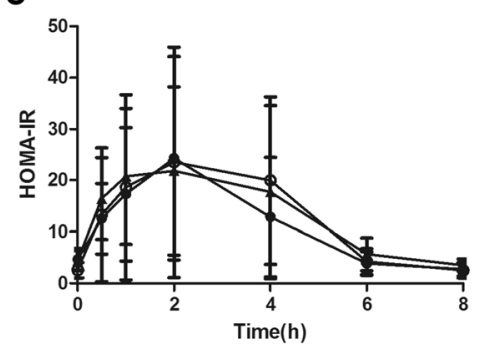

\section{d}

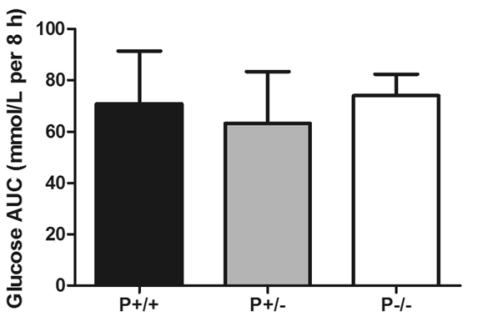

e

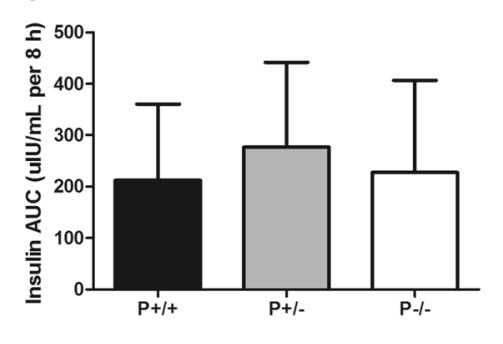

f

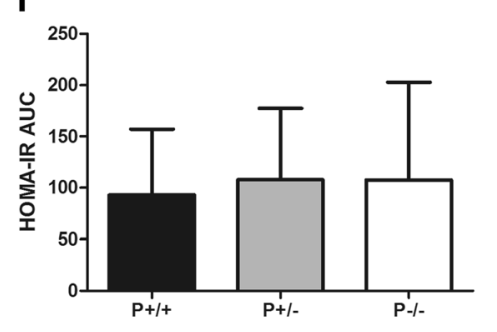

Fig. 4 The influence of Pvull polymorphisms on postprandial glycemic status. Left panel: Serum (a) glucose, (b) insulin and (c) HOMA-IR levels over the postprandial period in type 2 diabetic patients with abdominal obesity according to Pvull phenotypes. Plotted values are means \pm SD. $\bullet$ $\mathrm{P}+/+(n=31) ; \boldsymbol{\Lambda}, \mathrm{P}+/-(n=16) ; 0, \mathrm{P}-/-(n=4)$. For the serum glucose, insulin and HOMA-IR responses, there was a significant time effect $(P<0.05)$ by repeated-measures ANOVA. Right panel: Postprandial (d) glucose, (e) insulin and (f) HOMA-IR AUCs in type 2 diabetic patients with abdominal obesity according to Pvull phenotypes. Bars represent means \pm SD. HOMA-IR, homeostasis model assessment-insulin resistance; AUC, areas under the curve

In our study, the distribution of PvuII genotypes did not differ in the three groups. However, the patients with at least one $\mathrm{P}+$ allele had a greater postprandial TG AUC than P- patients. It is especially noteworthy that $\mathrm{P}-/-$ group was limited to a few samples, which mostly caused by the low frequency in Chinese populations. Additional data are needed to clarify the contribution of PvuII polymorphisms of LPL to postprandial lipemia.

Our study had several limitations. First, the main results of this study reflect an acute postprandial response which may not predict what happens chronically. Second, there are too few subjects with $\mathrm{P}-/-$ to be able to draw firm conclusions. Third, no data are available regarding hunger, fullness, and desire to eat collected on the subjects. Finally, results from a selective group cannot be assumed to apply to the total diabetic population.

To study postprandial lipemia, a variety of fat loading tests such as different food type, total food intake, fat content and time points for blood sample collections have been used, which make it difficult to compare results across studies. Here we use a liquid test meal as proposed by Schrezenmeir et al. [31]. It is proved to be fast and simple, and can eliminate the metabolic difference caused by the time of chewing food and mastication masticatory performance. In addition, the amount of food intake is adjusted to Dietary Guidelines for Chinese Residents, based on body weight rather than body surface area. The corresponding contribute rate of fat in total energy was $56.9 \%$, with similar proportion in several other studies $[5,7,20,21,32]$. This approach not only brings efficiency with respect to calculation but also satisfies the various energy requirements of subjects. Moreover, blood collection in fasting and postprandial state at $0.5,1,2,4,6$ and $8 \mathrm{~h}$ can accurately reveal the postprandial state of lipid. 


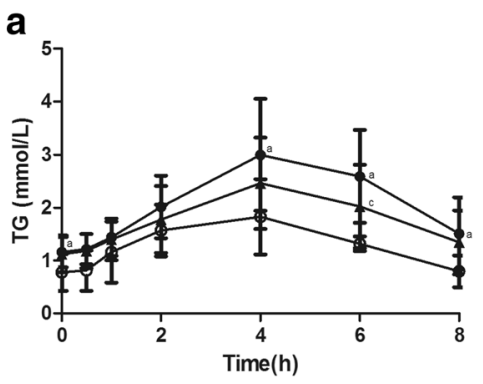

b

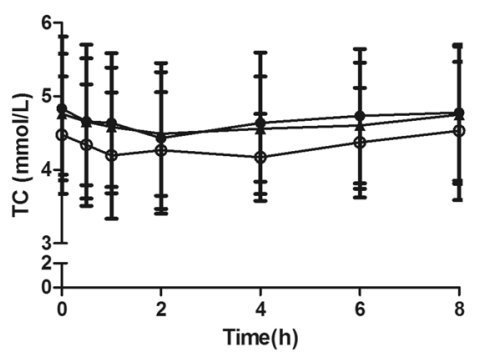

C

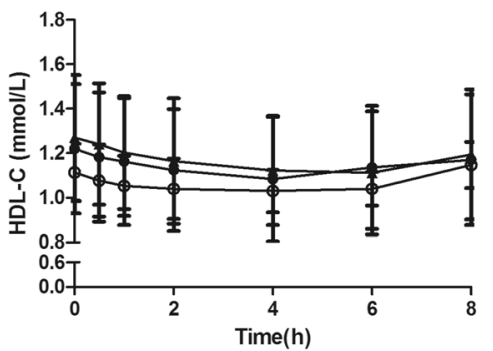

d

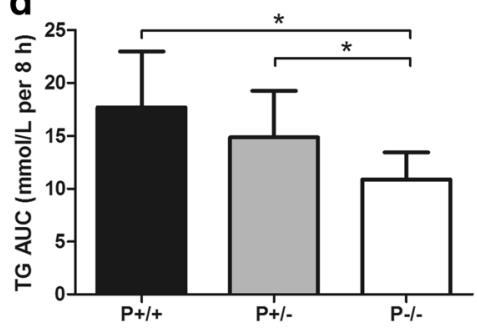

e

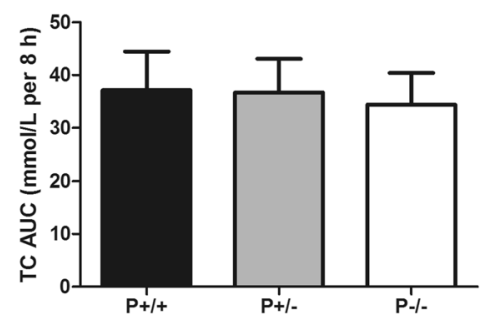

f

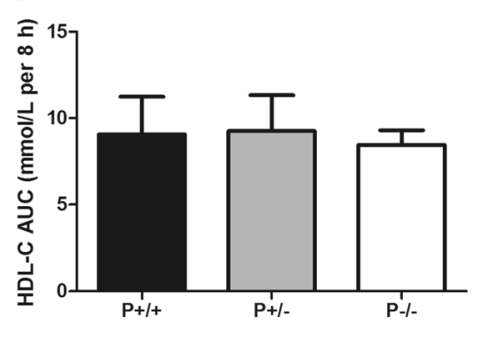

Fig. 5 The influence of Pvull polymorphisms on postprandial lipid status. Left panel: Serum (a) TG, (b) TC and (c) HDL-C levels over the postprandial period in type 2 diabetic patients with abdominal obesity according to Pvull phenotypes. Plotted values are means \pm SD. $\bullet, P+/+(n=31) ; \boldsymbol{\Lambda}, P+/-(n=16) ; 0, P$ $-/-(n=4) .{ }^{a} P<0.05, P+/+$ vs $P-/-,{ }^{b} P<0.05, P+/+$ vs $P+/-,{ }^{c} P<0.05, P+/-$ vs $P-/-$. For the serum TG, TC and HDL-C responses, there was a significant time effect $(P<0.05)$ by repeated-measures ANOVA. Right panel: Postprandial (d) TG, (e) TC and (f) HDL-C AUCs in type 2 diabetic patients with abdominal obesity according to Pvull phenotypes. Bars represent means $\pm S D$. ${ }^{*} P<0.05$. TG, triglyceride; TC, total cholesterol; HDL-C, high density lipoprotein cholesterol; AUC, areas under the curve

\section{Conclusions}

In summary, abdominal obesity exacerbates the postprandial lipid responses in type 2 diabetic patients, which partly explains the excess atherogenic risk in these patients. In addition, the presence of $\mathrm{P}+$ allele could contribute to a greater postprandial TG increase in type 2 diabetic patients with abdominal obesity. Further studies are required to elucidate the mechanisms responsible for the altered postprandial lipid profiles in type 2 diabetic patients with abdominal obesity.

\section{Abbreviations}

AUC: Areas under the curve; Cl: Confidence interval; HDL-C: High density lipoprotein cholesterol; HOMA-IR: Homeostasis model assessment-insulin resistance; IQR: Interquartile range; LPL: Lipoprotein lipase; LSMD: Least square mean difference; TC: Total cholesterol; TG: Triglyceride

\section{Acknowledgements}

We thank Nanjing Jiangpu People Hospital for recruiting research subjects. We are indebted to all the people who kindly participated in this study.

\section{Funding}

This study was supported by the grant from the National Natural Science Foundation of China (No. 81573144), the National Key Research and Development Program of China (No. 2016YFD0400604), the Fundamental Research Funds for the Central Universities (No. 2242015 K42109), and the Natural Science Foundation of the Higher Education Institutions of Jiangsu Province (NO.15KJB330004).

\section{Availability of data and materials}

The datasets used during the current study are available from the corresponding author on reasonable request.

\section{Authors' contributions}

FW and $\mathrm{HL}$ designed and performed the experiments, analyzed the data and wrote the manuscript. FL, HC and ZS were responsible for the conduct and monitoring of the experiments. FG, YX and GS participated in the biochemical analysis. GS supervised the research and reviewed the manuscript throughout the study. All authors read and approved the final manuscript.

\section{Ethics approval and consent to participate}

This study was approved by the ethic committee of Zhongda hospital affiliated to Southeast University. All of the participants agreed and signed informed consent before being tested. 


\section{Consent for publication}

Not applicable.

\section{Competing interests}

The authors declare that they have no competing interests.

\section{Publisher's Note}

Springer Nature remains neutral with regard to jurisdictional claims in published maps and institutional affiliations.

\section{Author details}

'Key Laboratory of Environmental Medicine and Engineering of Ministry of Education, and Department of Nutrition and Food Hygiene, School of Public Health, Southeast University, Nanjing, China. ${ }^{2}$ Zhongda Hospital, Southeast University, Nanjing, China. ${ }^{3}$ School of Public Health, Ningxia Medical University, Yinchuan, China. ${ }^{4}$ Second Clinical Medical College, Nanjing University of Traditional Chinese Medicine, Nanjing, China.

\section{Received: 29 April 2017 Accepted: 6 August 2017}

\section{Published online: 14 August 2017}

\section{References}

1. Zilversmit DB. Atherogenesis: a postprandial phenomenon. Circulation. 1979, 60:473-85.

2. Groot PH, van Stiphout WA, Krauss XH, Jansen $H$, van Tol A, van Ramshorst $E$, et al. Postprandial lipoprotein metabolism in normolipidemic men with and without coronary artery disease. Arterioscler Thromb. 1991;11:653-62.

3. Simons LA, Dwyer T, Simons J, Bernstein L, Mock P, Poonia NS, et al. Chylomicrons and chylomicron remnants in coronary artery disease: a casecontrol study. Atherosclerosis. 1987;65:181-9.

4. Mamo JC, Watts GF, Barrett PH, Smith D, James AP, Pal S. Postprandial dyslipidemia in men with visceral obesity: an effect of reduced LDL receptor expression? Am J Physiol Endocrinol Metab. 2001;281:E626-32.

5. Moreno LA, Quintela I, Fleta J, Sarria A, Roda L, Giner A, et al. Postprandial triglyceridemia in obese and non-obese adolescents. Importance of body composition and fat distribution. J Pediatr Endocrinol Metab. 2001;14:193-202.

6. Otokozawa S, Ai M, Diffenderfer MR, Asztalos BF, Tanaka A, Lamon-Fava S, et al. Fasting and postprandial apolipoprotein B-48 levels in healthy, obese, and hyperlipidemic subjects. Metab Clin Exp. 2009:58:1536-42.

7. de Ugarte MT, Portal VL, Dias AA, Schaan BD. Metabolic response to ora lipid overload in diabetes and impaired glucose tolerance. Diabetes Res Clin Pract. 2005:69:36-43.

8. Axelsen M, Smith U, Eriksson JW, Taskinen MR, Jansson PA. Postprandial hypertriglyceridemia and insulin resistance in normoglycemic first-degree relatives of patients with type 2 diabetes. Ann Intern Med. 1999;131:27-31.

9. Al-Disi DA, Al-Daghri NM, Khan N, Alfadda AA, Sallam RM, Alsaif M, et al. Postprandial Effect of a High-Fat Meal on Endotoxemia in Arab Women with and without Insulin-Resistance-Related Diseases. Nutrients. 2015;7:6375-89.

10. Kumar V, Madhu SV, Singh G, Gambhir JK. Post-prandial hypertriglyceridemia in patients with type 2 diabetes mellitus with and without macrovascular disease. J Assoc Physicians India. 2010;58:603-7.

11. Madhu SV, Kant S, Srivastava S, Kant R, Sharma SB, Bhadoria DP. Postprandial lipaemia in patients with impaired fasting glucose, impaired glucose tolerance and diabetes mellitus. Diabetes Res Clin Pract. 2008;80:380-5.

12. Madhu SV, Mittal V, Ram BK, Srivastava DK. Postprandial lipid abnormalities in type 2 diabetes mellitus. J Assoc Physicians India. 2005;53:1043-6.

13. Suryabhan LL, Chandrashekhar MI, Ratnendra RS, Prerna DN. A comparative study on the fasting and the postprandial dyslipidaemia in type 2 diabetes mellitus. J Clin Diagn Res. 2013;7:627-30.

14. Chan DC, Barrett HPR, Watts DGF. Dyslipidemia in Visceral Obesity. Am J Cardiovasc Drugs. 2004;4:227-46.

15. Shin E, Park NY, Jang Y, Oh H, Jeong J, Lim Y, et al. The association of lipoprotein lipase Pvull polymorphism and niacin intake in the prevalence of metabolic syndrome: a KMSRI-Seoul study. Genes Nutr. 2012;7:331-41.

16. Duman BS, Turkoglu C, Akpinar B, Guden M, Vertii A, Dak E, et al. Lipoprotein lipase gene polymorphism and lipid profile in coronary artery disease. Arch Pathol Lab Med. 2004;128:869-74.

17. Alberti KG, Zimmet PZ. Definition, diagnosis and classification of diabetes mellitus and its complications. Part 1: diagnosis and classification of diabetes mellitus provisional report of a WHO consultation. Diabet Med. 1998;15:539-53.
18. WGOC. Guidelines for the prevention and control of overweight and obesity among Chinese adults (Excerpt). Acta Nutrimenta Sin. 2004;26:1-4.

19. Matthews DR, Hosker JP, Rudenski AS, Naylor BA, Treacher DF, Turner RC. Homeostasis model assessment: insulin resistance and beta-cell function from fasting plasma glucose and insulin concentrations in man. Diabetologia. 1985;28:412-9.

20. Annuzzi G, Giacco R, Patti L, Di Marino L, De Natale C, Costabile G, et al. Postprandial chylomicrons and adipose tissue lipoprotein lipase are altered in type 2 diabetes independently of obesity and whole-body insulin resistance. Nutr Metab Cardiovasc Dis. 2008;18:531-8.

21. Annuzzi G, De Natale C, lovine C, Patti L, Di Marino L, Coppola S, et al. Insulin resistance is independently associated with postprandial alterations of triglyceride-rich lipoproteins in type 2 diabetes mellitus. Arterioscler Thromb Vasc Biol. 2004;24:2397-402.

22. Cooper MB, Tan KC, Hales CN, Betteridge DJ. Postprandial lipid metabolism and beta-cell function in non-insulin-dependent (type 2) diabetes mellitus after a mixed meal with a high fat content. Diabet Med. 1996;13:816-27.

23. Wagner AM, Ordonez-Llanos J, Arcelus R, Bonet R, Jorba O, SanchezQuesada $J$, et al. Postprandial lipidemia is normal in non-obese type 2 diabetic patients with relatively preserved insulin secretion. Metab Clin Exp. 2003:52:1038-42.

24. Pirro M, Lupattelli G, Siepi D, Palumbo B, Roscini AR, Marchesi S, et al. Postprandial lipemia and associated metabolic disturbances in healthy and hyperlipemic postmenopausal women. Metab Clin Exp. 2001:50:330-4.

25. Westerveld HT, Meijer E, Erkelens DW, de Bruin TW. Postprandial reduction in high-density lipoprotein cholesterol concentrations in postmenopausal women: improvement by 17beta-estradiol. Metab Clin Exp. 1996;45:827-32.

26. Sutherland WH, de Jong SA, Walker RJ. Effect of dietary cholesterol and fat on cell cholesterol transfer to postprandial plasma in hyperlipidemic men. Lipids. 2007:42:901-11.

27. Al-Jafari AA, Cryer A. The lipoprotein lipase of white adipose tissue. Studies on the intracellular distribution of the adipocyte-associated enzyme. Biochem J. 1986:236:749-56.

28. Daoud MS, Ataya FS, Fouad D, Alhazzani A, Shehata Al, Al-Jafari AA. Associations of three lipoprotein lipase gene polymorphisms, lipid profiles and coronary artery disease. Biomed Rep. 2013;1:573-82.

29. Bozina T, Simic I, Lovric J, Pecin I, Jelakovic B, Sertic J, et al. Effects of lipoprotein lipase and peroxisome proliferator-activated receptor-gamma gene variants on metabolic syndrome traits. Coll Antropol. 2013;37:801-8.

30. Socquard E, Durlach A, Clavel C, Nazeyrollas P, Durlach V. Association of HindIII and Pvull genetic polymorphisms of lipoprotein lipase with lipid metabolism and macrovascular events in type 2 diabetic patients. Diabetes Metab. 2006;32:262-9.

31. Schrezenmeir J, Weber P, Probst R, Biesalski HK, Luley C, Prellwitz W, et al. Postprandial pattern of triglyceride-rich lipoprotein in normal-weight humans after an oral lipid load: exaggerated triglycerides and altered insulin response in some subjects. Ann Nutr Metab. 1992;36:186-96.

32. Tentolouris N, Stylianou A, Lourida E, Perrea D, Kyriaki D, Papavasiliou EC, et al. High postprandial triglyceridemia in patients with type 2 diabetes and microalbuminuria. J Lipid Res. 2007:48:218-25.

\section{Submit your next manuscript to BioMed Central and we will help you at every step:}

- We accept pre-submission inquiries

- Our selector tool helps you to find the most relevant journal

- We provide round the clock customer support

- Convenient online submission

- Thorough peer review

- Inclusion in PubMed and all major indexing services

- Maximum visibility for your research

Submit your manuscript at www.biomedcentral.com/submit
) Biomed Central 